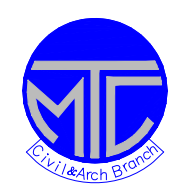

ICCAE

Military Technical College Kobry Elkobbah,

Cairo, Egypt
$7 \underline{\text { th }}$ International Conference

On Civil \& Architecture

Engineering

\title{
ENHANCEMENT OF IMPACT RESISTANCE OF CONCRETE USING INNOVATIVE SHAPE OF STEEL FIBRES
}

\author{
N . H . Amer*
}

\section{ABSTRACT}

Concrete is oftenly subjected to impact and other dynamic loads in service. These loads may occur due to blasts, traffic, and seismic activity. To enhance the impact resistance of concrete, many types of fibers can be used. In this research, two shapes of steel fibres are used: hook-ended shape (SF) and a new spiral shape (SSF) Fig.1. The innovative shape is introduced manually in fresh concrete with suitable vertical and horizontal alignment.

The test program is designed to study the effect of SF, and SSF on the impact resistance of concrete and selected mechanical properties. The two shapes of steel fibres were added at the fraction volume of $0.5 \%, 1.0 \%, 2.0 \%$, and $3.0 \%$. The compressive strength of steel fibers reinforced concrete (SFRC) enhanced by $43.4 \%$ at $2.0 \%$ volume fraction relative to plain concrete. The compressive strength of spiral steel fibers reinforced concrete (SSFRC) enhanced by a 65\% at 3.0\% volume fraction relative to plain concrete. The splitting tensile strength and modulus of rupture of SFRC improved with increasing of fiber volume fraction recording $52.6 \%$ and $137.5 \%$ enhancement, respectively, at $2.0 \%$ volume fraction. The splitting tensile strength and modulus of rupture of interlocked spiral steel fibres (SSFRC*) improved with the increase in volume fraction up to $3.0 \%$, recording $147 \%$ and $62.5 \%$ enhancement, respectively. Also, The toughness index of SFRC enhanced with the increase in the fraction up to $2.0 \%$. The toughness indices $I_{5}, I_{10}$, and $I_{20}$ registered values of 10.7, 20.5, and 35.1, respectively, at $2.0 \%$ fraction volume. The toughness index of SSFRC* enhanced with increasing the fraction volume up to $3.0 \%$. The indices $\mathrm{I}_{5}, \mathrm{I}_{10}$, and $\mathrm{I}_{20}$ recorded values of $9.76,18.78$, and 35.8 , respectively, at $3.0 \%$ fraction volume. 
The impact resistance of SFRC improved with the increase in the fiber content up to $2.0 \%$, recording 33 times that of the impact resistance of plain concrete, at $2.0 \%$ fraction volume. The impact resistance of SSFRC* enhanced with the increase in the fiber volume fraction recording 116 times the impact resistance of plain concrete, at 3.0\% fraction volume.

Key Words: Reinforced Concrete; Steel Fibers; Strengthening; Impact; Mechanical Properties.

\section{INTRODUCTION}

Resistance to impact loads is recognized today as one of the significant properties of concrete used for structural applications. It is well known that fibre-reinforced concrete generally has good fracture toughness and impact resistance compared to plain concrete [1]. This paper studies the impact resistance of plain concrete, SFRC, and SSFRC (vertical- horizontal-vertically interlocked spirals Fig.1). The impact resistance of concrete was determined using drop-weight falling from $30 \mathrm{~cm}$ height on 100x100x500 mm beams and the number of blows was recorded at failure [9].

Laboratory studies were carried out on concrete specimens (cubes, cylinders, beams), which are prepared by adding two shapes of steel fibres (Hooked ended with aspect ratio=50), and an innovative shape of steel fibres (spiral shape with diameter 2.5, $1.5 \mathrm{~cm}$ and variable length). The two shapes of fibers have the same mechanical properties, and it was added by amount of $(0.5,1.0,2.0$, and $3.0 \%)$ by volume. The experimental investigation is discussed in the next section showing the characteristics of materials used, design of mixes, tests on specimens, and equipments used. 
The main objectives of the present research focused on the evaluation of new shape of steel fibres (spiral shape) and studying the effect of using this new technique on the impact resistance of concrete by:

1. Controlling of the fibres content avoiding problem in workability and compaction (no balling or clumping), by introducing the SSF with suitable way and length, according to the dimensions of specimens.

2. Controlling of the orientation and alignment of fibres (vertical or horizontal). This means uniform distribution of fibres rather than random.

3. Enhancing the bond between fibres and the matrix by using spiral shape rather than hooked end ones.

4. Enhancing the capacity of spiral fibres by interlocking them together in some cases. This means the change in failure mode by de-bonding (fractured) fibre rather than pulling-out.
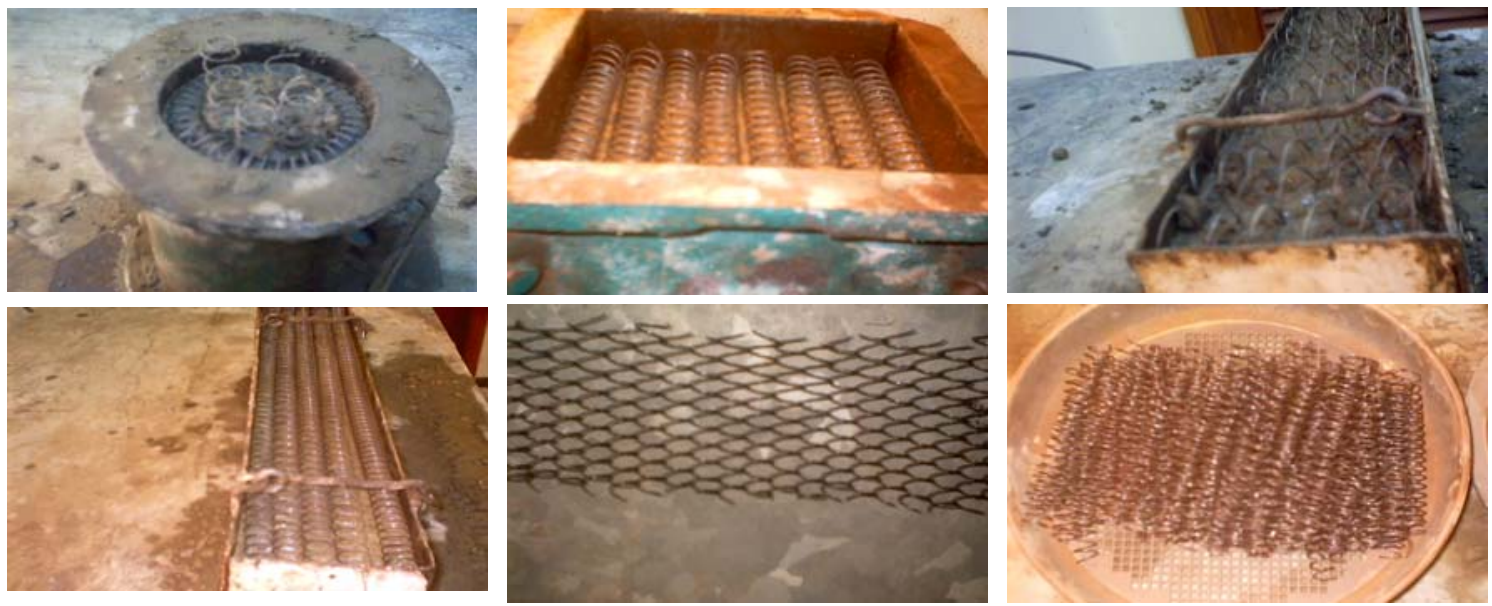

Fig.1. Introducing spiral fibres into fresh concrete specimens

\section{EXPERIMENTAL PROGRAM}




\subsection{Materials Used}

Type I cement, sand and crushed rock from quarrying operations of 6.3 maximum sizes were used. Super plasticizers based on naphthalene formaldehyde condensate were used as workability agents to ensure the desired strength without increasing the water-cement ratio. The cement, sand, crushed rock, water, super plasticizers of $400,918,918,180$, and $6 \mathrm{~kg} / \mathrm{m}^{3}$ were used to make the plain concrete. The V-B time was ranged from 9 second to 22 second. The hook-ended and spiral steel fibres were made of mild carbon steel. The hook-ended fibers have an average length of $50 \mathrm{~mm}$, nominal diameter of $1.0 \mathrm{~mm}$, and the aspect ratio of 50 . The spiral fibres have a variable length according to dimensions of specimens.

\subsection{Preparations Of Samples}

In the production of concrete, the constituent materials were initially mixed without fibres [5]. The hooked-end fibres were then added in small amounts to avoid fibre balling and to produce concrete with uniform material consistency and good workability. The spiral steel fibres were placed manually in layers before and during the casting of fresh concrete. Mixing time was prolonged from 3 minutes for the conventional mixture to 5 minutes for the SFRC to ensure a homogeneous fibre distribution. The mix was placed into a beam mold to cast a standard 100x100x500 concrete beams. Each layer was consolidated using a vibrating table. At the end of 24h after consolidating, the specimens were removed from the mold and cured in water at $23^{0} \mathrm{C}$ for 28 days [8].

\subsection{Test Methods}


Impact is applied using a falling mass striking the concrete beam. The impact produces a load pulse on the beam and this pulse again results in strain and deflections of the beam [6]. The impact releases an amount of energy which is determined by the weight of the falling body and the falling height. The energy is calculated according to the following relation:

$$
\mathrm{E}=\text { Mass }(\mathrm{Kg}) \times \text { Height }(\mathrm{m}) \times \mathrm{g}\left(\mathrm{m} / \mathrm{sec}^{2}\right)
$$

In this study, impact resistance of SFRC is measured by a test using a 4.2 $\mathrm{kg}$ mass falling onto mid point of $(100 \times 100 \times 500 \mathrm{~mm})$ beams from $0.3 \mathrm{~m}$ height. The numbers of blows required for cracking of specimens are recorded. Also, using the innovative shape (spiral shape) the similar tests are experimented for vertical and horizontal alignment of spirals in the beam. In addition to testing SSFRC beams, special case by interlocking spiral fibres in vertical alignment is tested, and in this case the test continued until deponding of spiral fibres.

\section{RESULTS AND DISCUSSION}

\subsection{Compressive Strength}

Table 1 shows the compressive strength test results on SFRC and SSFRC. Each strength test result was the average for 3 test specimens [4]. The compressive strength enhancement of SSFRC versus SFRC is shown in Fig.2. The cube compressive strength of plain concrete was $32.55 \mathrm{~N} / \mathrm{mm}^{2}$ and an improvement for SFRC at each volume fraction was noticed. The improvement, (strength-enhancement) as shown in Table l and Fig.2, was 10.2 at $0.5 \%$ fraction volume, $29.2 \%$ at $1.0 \%$ fraction volume, and reduced to $18.3 \%$, and $14.5 \%$ at $2.0 \%$, and $3.0 \%$ fraction volume, respectively. The cylinder compressive strength of plain concrete was $28.1 \mathrm{~N} / \mathrm{mm}^{2}$ and for SFRC, an improvement at each volume fraction shown in Table 1, and Fig.2.

Table 1: Compressive strength test results and strength-enhancement for SFRC and SSFRC 


\begin{tabular}{|c|c|c|c|c|c|c|c|c|c|c|c|c|c|c|c|c|c|}
\hline \multirow{3}{*}{$\begin{array}{c}\text { Fibre } \\
\text { Volume } \\
\text { Fraction } \\
\text { (\%) }\end{array}$} & \multicolumn{9}{|c|}{ Cube compressive strength } & \multicolumn{8}{|c|}{ Cylinder compressive strength } \\
\hline & \multicolumn{4}{|c|}{ SFRC } & \multicolumn{5}{|c|}{ SSFRC } & \multicolumn{4}{|c|}{ SFRC } & \multicolumn{4}{|c|}{ SSFRC } \\
\hline & 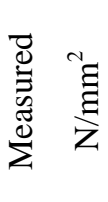 & 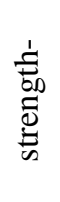 & 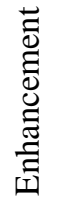 & d & 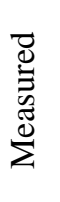 & 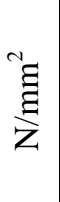 & 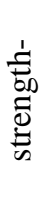 & 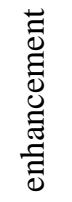 & d & 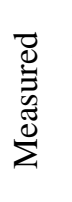 & ${ }^{N}$ & 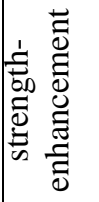 & $\mathfrak{d}^{\mathfrak{a}}$ & 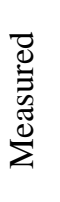 & $\frac{{ }^{N}}{\Xi}$ & 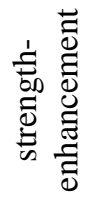 & $\overbrace{}^{0}$ \\
\hline 0 & 32.55 & & - & & 32. & & & - & & 28. & & & - & 28 & & - & \\
\hline 0.5 & 35.88 & & 10.2 & & 35. & & & 10.2 & & 32. & & & 5.3 & 32 & & 15.6 & \\
\hline 1.0 & 42.07 & & 29.2 & & 41. & & & 27.7 & & 37. & & & 3.4 & 37 & & 31.6 & \\
\hline 2.0 & 38.5 & & 18.3 & & 44 & & & 35.8 & & 33. & & & 9.2 & 39 & & 40.5 & \\
\hline 3.0 & 36.4 & & 14.5 & & 48 & & & 47.4 & & 32. & & & 16 & 43 & & 55.8 & \\
\hline
\end{tabular}

Fibre concrete -plain concrete

Strength-enhancement \% = Plain concrete
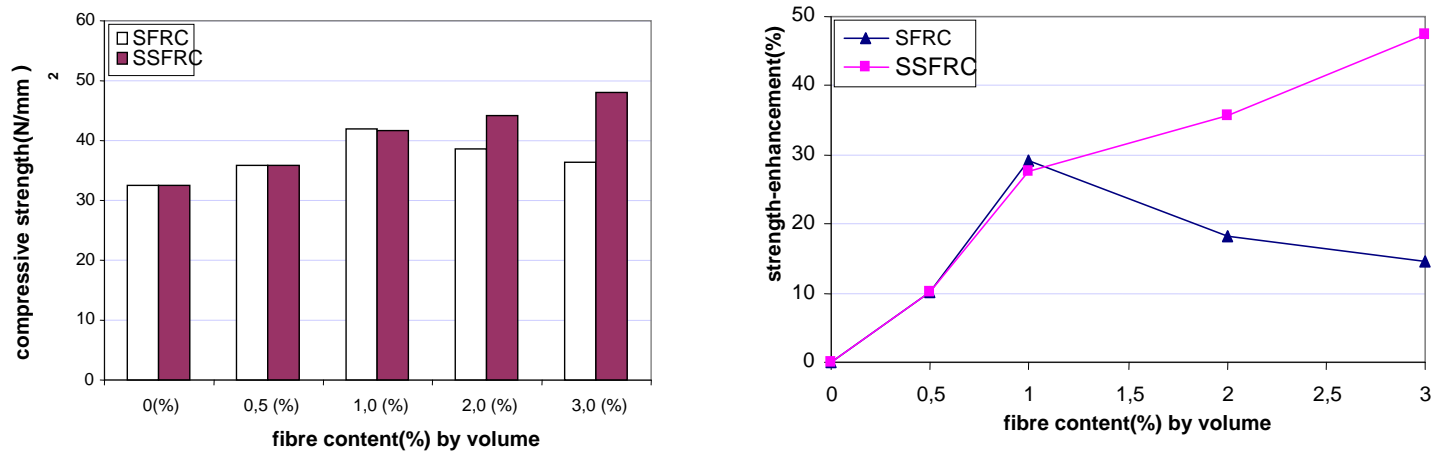

Fig.2. Relation between compressive strength-enhancement $\%$ and fibre content\% by volume

The compressive strength enhancement of SSFRC versus plain concrete is shown in Table 1. The cube compressive strength of plain concrete was 32.55 $\mathrm{N} / \mathrm{mm}^{2}$ and an enhancement for SSFRC at each volume fraction was noticed. The improvement, as the strength-enhancement is shown in Table 1, was 10.2 at $0.5 \%$ fraction volume, $27.7 \%$ at $1.0 \%$ fraction volume, $35.8 \%$ at $2.0 \%$ fraction volume, and $47.4 \%$ at $3.0 \%$ fraction volume. The cylinder compressive strength of plain concrete was $28.1 \mathrm{~N} / \mathrm{mm}^{2}$ and for SSFRC, an improvement at each volume fraction is shown in Table 1, and Fig.2.

\subsection{Splitting Tensile Strength}


The enhancement in splitting tensile strength of SFRC at various volume fractions relative to plain concrete is shown in Table 2. The strength of SFRC improved with increasing the volume fraction up to $2.0 \%$. The improvement started from $16.7 \%$ at $0.5 \%$ fraction volume and extended to $49 \%$ at $2.0 \%$ fraction volume, but reduced to $38 \%$ at $3.0 \%$ fraction volume. However, the optimum limit could be considered at $2 \%$ volume fraction. The development of splitting tensile strength of SSFRC at various volume fractions is shown in Table. 2. Compared to plain concrete, the strength of SSFRC improved with increasing the volume fraction up to $3.0 \%$. From the results of strengthenhancement in Table 2, the improvement started from $25.2 \%$ at $0.5 \%$ fraction volume and extended to $85.5 \%$ at $3.0 \%$ fraction volume [9]. The comparison between the enhanced gained by each type is illustrated in Fig.3.

Table (2) Tensile strength test results and strength-enhancement on SFRC and SSFRC

\begin{tabular}{|c|c|c|c|c|c|c|c|c|c|c|}
\hline \multirow{3}{*}{$\begin{array}{c}\text { Fibre } \\
\text { Volume } \\
\text { Fraction } \\
(\%)\end{array}$} & \multicolumn{4}{|c|}{ Splitting tensile strength } & \multicolumn{6}{|c|}{ Flexural tensile strength (MOR) } \\
\hline & \multicolumn{2}{|c|}{ SFRC } & \multicolumn{2}{|c|}{ SSFRC } & \multicolumn{2}{|c|}{ SFRC } & \multicolumn{2}{|c|}{ SSFRC(H) } & \multicolumn{2}{|c|}{ SSFRC* } \\
\hline & 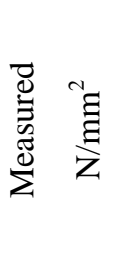 & 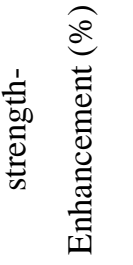 & 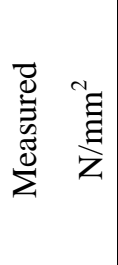 & 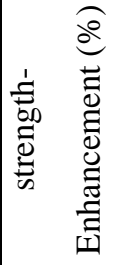 & 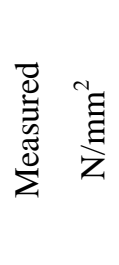 & 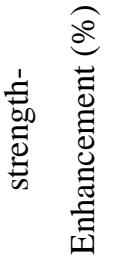 & 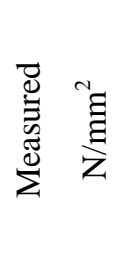 & 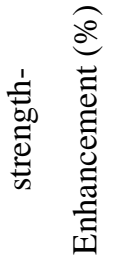 & 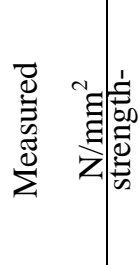 & 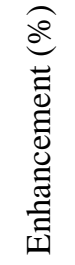 \\
\hline 0 & 3.1 & - & 3.1 & - & 3.2 & - & 3.2 & - & 3.2 & - \\
\hline 0.5 & 3.62 & 16.7 & 3.88 & 25.2 & 3.6 & 12.5 & 3.27 & 2.2 & 3.4 & 6.25 \\
\hline 1.0 & 4.43 & 43 & 4.56 & 47 & 5.6 & 75 & 3.43 & 7.2 & 3.48 & 8.75 \\
\hline 2.0 & 4.62 & 49 & 5.08 & 64 & 7.6 & 137.5 & 3.45 & 8 & 4.4 & 37.5 \\
\hline 3.0 & 4.28 & 38 & 5.75 & 85.5 & 6.2 & 93.7 & 3.46 & 8.1 & 5.2 & 62.5 \\
\hline
\end{tabular}

Fibre concrete strength -plain concrete strength

Strength-enhancement \% =

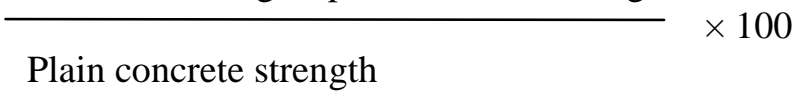

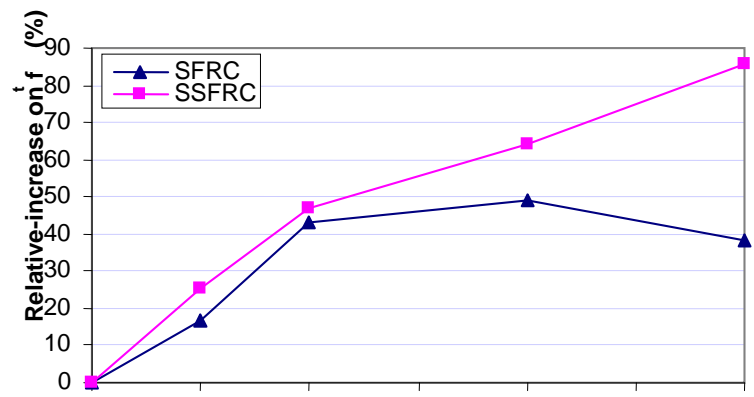


Fig.3. Relative-increase in splitting tensile strength enhancement $\%$ and fibre content\% by volume

\subsection{Modulus Of Rupture (MOR)}

The MOR for SFRC at various volume fractions is shown in Table. 2. Also, the strength-enhancement is illustrated in Table 2 indicating that the MOR values were higher by $12.5 \%, 75 \%, 137.5 \%$, at the fractions of $0.5 \%$, $1.0 \%$, and $2.0 \%$, respectively, compared to plain concrete. But the enhancement reduced to $93.7 \%$ at $3.0 \%$ fraction volume.

The MOR for horizontally aligned SSFRC improved slightly with increasing the volume fraction from $2.2 \%$ to $7.2 \%$ to $8 \%$ to $8.1 \%$ with fibre content $0.5 \%, 1.0 \%, 2.0 \%$, and $3.0 \%$, respectively. This can be attributed to the expanding of spirals after cracks at mid span of beam, in absence of high effect of fibres to resist the tensile stress at first crack as in case of plain concrete.

The MOR for SSFRC*(interlocking spiral) improved from $6.25 \%$ to $8.75 \%$ to $37.5 \%$ to $62.5 \%$ with fibre content $0.5,1.0,2.0$, and $3.0 \%$, respectively due to the absence of voids, balling, and clumping in spiral fibres.

\subsection{Flexural Toughness}


Flexural toughness is the energy absorbed in deflecting beam by a specified amount, being the area under a load-deflection $(P-\delta)$ curve for the 100x100x500mm beam tested at third-point in bending [9]. Index toughness (I) for SFRC, SSFRC, and SSFRC* reflects the improvement in flexural toughness over the non-reinforced concrete. The widely estimated indices are 15 at 38, $I 10$ at 5.58, and $I 20$ at 10.58 . All the three indices reached unity, assuming that the non fibre-reinforced matrix is elastic-brittle. Such results are illustrated in Table 3. For SFRC the toughness indices increased their values with increasing volume fraction of fibres up to $2.0 \%$. The 15 , /I10, and I20 values were 10.7, 20.5, and 35.1, respectively, at the fraction of $2.0 \%$. But the values decreased to $8.6,14.54$, and 22.19 with volume fraction $3.0 \%$, compared with the values at $2.0 \%$ volume fraction. For SSFRC* (interlocking), the toughness indices increased their values with increasing volume fraction of fibres up to $3.0 \%$. The $15, I 10$, and I20 values were 9.76, 18.78, and 35.8, respectively, at the fraction of 3.0\% Fig.4, 5 and 6.

Table 3 : Flexural toughness indices at various fibre volume fractions for SFRC and SSFRC*

\begin{tabular}{|c|c|c|c|c|c|c|}
\hline \multirow{2}{*}{$\begin{array}{c}\text { Fibre } \\
\text { Volume } \\
\text { Fraction (\%) }\end{array}$} & \multicolumn{3}{|c|}{ SFRC } & \multicolumn{3}{|c|}{ SSFRC*(interlocking) } \\
\cline { 2 - 7 } & \multicolumn{3}{|c|}{ toughness index } & \multicolumn{3}{|c|}{ toughness index } \\
\cline { 2 - 7 } & $\mathrm{I}_{5}$ & $\mathrm{I}_{10}$ & $\mathrm{I}_{20}$ & $\mathrm{I}_{5}$ & $\mathrm{I}_{10}$ & $\mathrm{I}_{20}$ \\
\hline 0 & 1.0 & 1.0 & 1.0 & 1.0 & 1.0 & 1.0 \\
\hline & 5.61 & 8.16 & 10.35 & 5.2 & 10.18 & 19 \\
\hline 1.0 & 8.41 & 15.8 & 23.9 & 5.32 & 10.92 & 22.5 \\
\hline 2.0 & 10.7 & 20.5 & 35.1 & 6.7 & 14.42 & 30.2 \\
\hline 3.0 & 8.6 & 14.54 & 22.19 & 9.76 & 18.78 & 35.8 \\
\hline
\end{tabular}
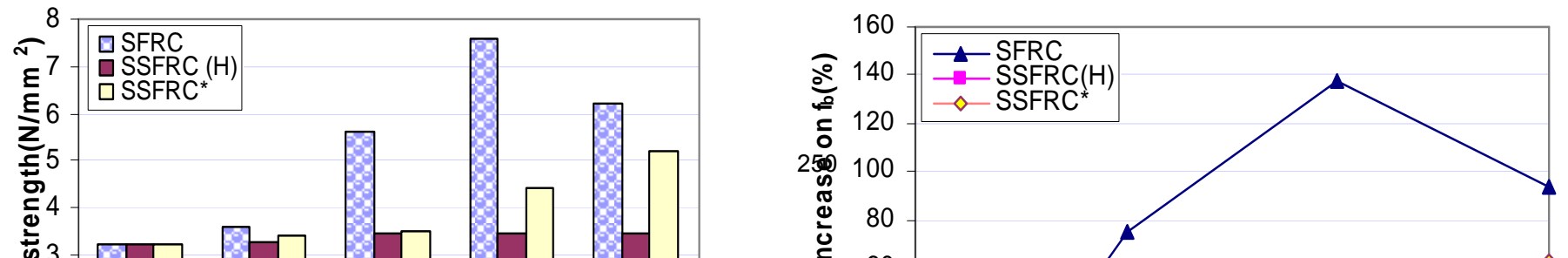
Fig.4. Relative-increase on flexural strength (\%)-enhancement\% and fibre content\% by volume

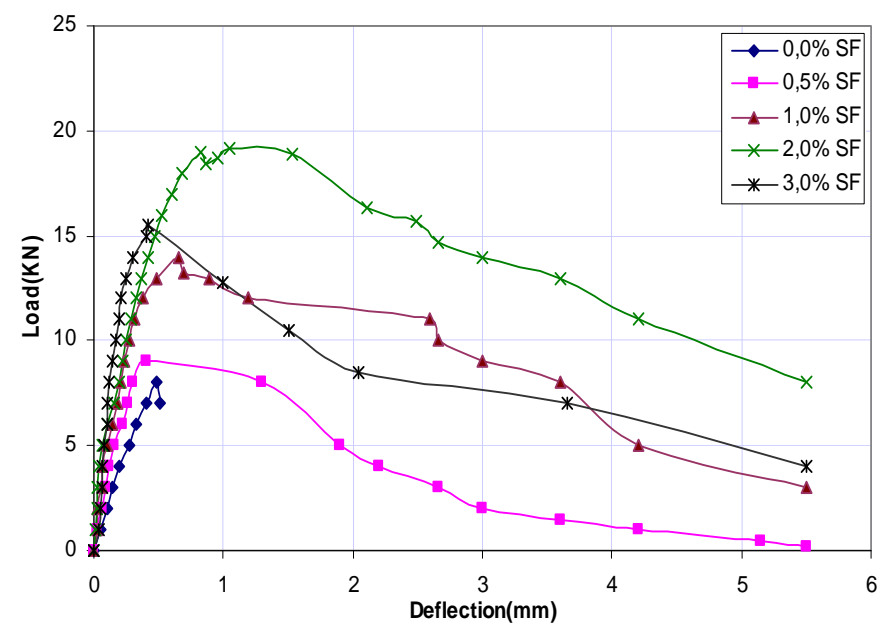

Fig.5. Load-deflection curves from deflection tests (Various content of SF)

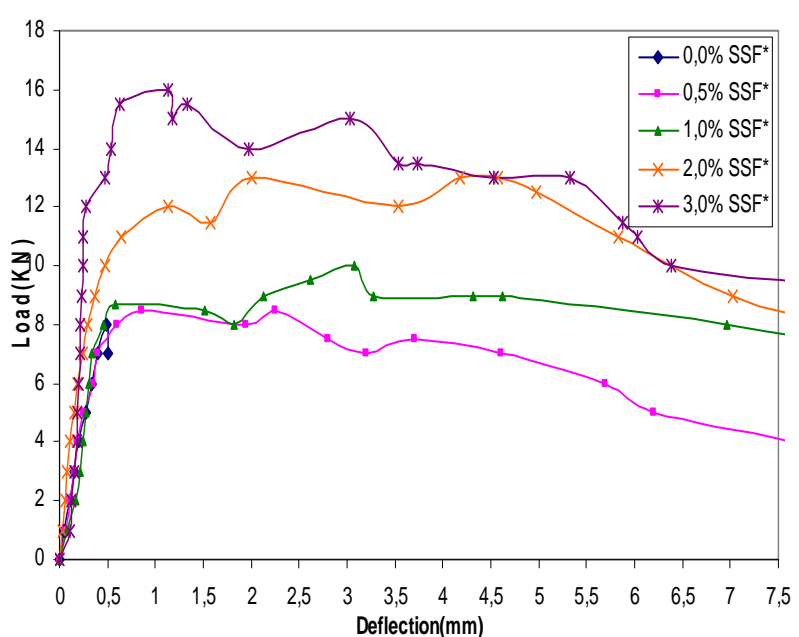

Fig.6. Load-deflection curves from deflection tests (various content of SSF*)

\subsection{Impact Resistance}

Table 4 presents the impact resistance test results on SFRC, SSFRC (V-H), and SSFRC*. Each strength test result was the average of three test specimens. The impact resistance of SFRC improved to different extents in response to fibre volume fractions up to $2.0 \%$.

Using SSF, the above property improved up to $3.0 \%$ fractions. It can be shown, compared with plain concrete, that is the impact resistance at initial cracking of SFRC was increased to twice of that with $0.5 \%$ fibre content to 
5.34 times with $2.0 \%$ fibre content, but was decreased to 4.33 times with fibre content 3.0\%, compared with value at 2.0\% volume fraction Fig.6.7.

It can be noticed; using SSF (V) and SSF (H) that there is noticeable enhancement in impact resistance compared with plain concrete. This can be attributed to separating spiral fibres from each other and generating crack openings between them, when using SSF (V). Also, it can be attributed to expanding the horizontal spirals at mid span of beam when using $\operatorname{SSF}(H)$, without high effect of fibre to resist impact loading nearly (such as in plain concrete). Using SSF*, the impact resistance at initial cracking of SSFRC* was increased from 2 times with $0.5 \%$ fibre to 3 times with 3.0\% fibre content by volume. Also, impact resistance at failure increased greatly from 62.5 times to 91.75 times to 98 times to 116.75 times with fibre content 0.5, 1.0, 2.0 , and $3.0 \%$ by volume, respectively Table 4 . This can be attributed to interlocking spiral fibres together and resist impact loading until de-bonding (fracture) rather than pullout, which means great energy absorption more than other types of fiber reinforced concrete.

Table 4: Impact resistance test results (28 days age) - relative increase in I.R. 
Proceedings of the 7th ICCAE Conf. 27 -29 May, 2008

\begin{tabular}{|c|c|c|c|c|c|c|c|c|}
\hline \multirow{3}{*}{\multicolumn{2}{|c|}{$\begin{array}{c}\text { Type } \\
\text { Of } \\
\text { Concrete }\end{array}$}} & \multirow{3}{*}{$\begin{array}{c}\text { Fibre } \\
\text { Volume } \\
\text { Fraction } \\
\text { \% }\end{array}$} & \multicolumn{4}{|c|}{ Impact resistance } & \multicolumn{2}{|c|}{ \% increase in I.R. } \\
\hline & & & \multicolumn{2}{|c|}{ Initial Cracking } & \multicolumn{2}{|c|}{ Failure } & \multirow[b]{2}{*}{$\begin{array}{c}\text { Initial } \\
\text { Cracking }\end{array}$} & \multirow[b]{2}{*}{ Failure } \\
\hline & & & $\begin{array}{l}\text { No. of } \\
\text { Blows }\end{array}$ & $\begin{array}{c}\text { I.R } \\
\text { (N.m) }\end{array}$ & $\begin{array}{l}\text { No. of } \\
\text { Blows }\end{array}$ & $\begin{array}{c}\text { I.R } \\
(\mathrm{N} . \mathrm{m})\end{array}$ & & \\
\hline \multirow{5}{*}{\multicolumn{2}{|c|}{ SFRC }} & 0 & 3 & 378 & 4 & 504 & - & - \\
\hline & & 0.5 & 6 & 756 & 40 & 5040 & 100 & 900 \\
\hline & & 1 & 8 & 1008 & 66 & 8316 & 167 & 1550 \\
\hline & & 2 & 16 & 2016 & 135 & 17010 & 434 & 3275 \\
\hline & & 3 & 13 & 1638 & 90 & 11340 & 333 & 2150 \\
\hline \multirow{8}{*}{ SSFRC } & $\mathrm{V}$ & \multirow{2}{*}{0.5} & 3 & 378 & 4 & 504 & - & - \\
\hline & $\mathrm{H}$ & & 3 & 378 & 4 & 504 & - & - \\
\hline & \multirow[b]{2}{*}{$\mathrm{H}$} & \multirow{2}{*}{1} & 3 & 378 & 5 & 630 & - & 25 \\
\hline & & & 3 & 378 & 5 & 504 & - & - \\
\hline & \multirow[b]{2}{*}{$\mathrm{H}$} & \multirow{2}{*}{2} & 3 & 378 & 8 & 630 & - & 25 \\
\hline & & & 3 & 378 & 7 & 504 & - & - \\
\hline & \multirow[b]{2}{*}{$\mathrm{H}$} & \multirow{2}{*}{3} & 3 & 378 & 5 & 630 & - & 25 \\
\hline & & & 3 & 378 & 4 & 504 & - & - \\
\hline \multirow{4}{*}{\multicolumn{2}{|c|}{ SSFRC* }} & 0.5 & 9 & 1134 & 250 & 31500 & 200 & 6150 \\
\hline & & 1 & 11 & 1386 & 367 & 46242 & 266 & 9075 \\
\hline & & 2 & 12 & 1512 & 392 & 49392 & 300 & 9700 \\
\hline & & 3 & 12 & 1512 & 467 & 58842 & 300 & 11575 \\
\hline
\end{tabular}
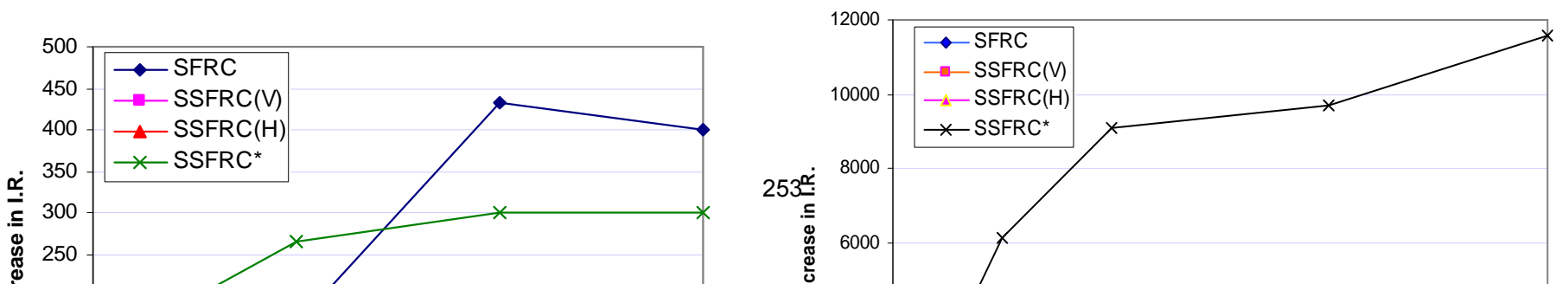


\section{CONCLUSIONS}

1. The compressive strength of plain concrete improved with addition of steel fibres up to $2.0 \%$ by volume, but decreased at $3.0 \%$ fraction compared to $2.0 \%$ fraction. The enhancement in compressive strength has reached $34 \%$.

2. Using spiral steel fibres increases the compressive strength with fibres content up to $3.0 \%$ by volume. The maximum enhancement reached $55.8 \%$ at $3.0 \%$ fraction.

3. The splitting tensile strength of concrete improved with increasing steel fibres up to $2.0 \%$ fraction, but decreased at $3.0 \%$ fraction. The maximum enhancement reached $49 \%$ at $2.0 \%$ fraction. Using spiral steel fibres, more enhancement with increasing the fibres content up to 3.0\% fraction is noticed. The maximum enhancement reached $85.5 \%$ at $3.0 \%$ fraction.

4. The addition of SF to plain concrete leads to an increase in the modulus of rupture of $138 \%$ at $2.0 \%$ fraction. But using SSF in different orientations, with and without interlocking the spirals, a little and different enhancement in values of modulus of rupture was noticed. Using, SSF (H), and SSF*(V) the enhancement reached $8.0 \%$, and $63 \%$, respectively at $3.0 \%$ fraction.

5. The ASTM toughness indices I5, I10, and I20 increased as SF content increased up to $2.0 \%$, but they decreased at $3.0 \%$ fraction compared to $2.0 \%$ 
fraction. The enhancement in toughness indices were 10.7, 20.5, and 35.1\%, respectively. Using SSF*, the toughness indices increased as SSF content increased up to $3.0 \%$ fraction and the enhancements were 9.76, 18.78, and 35.8, respectively.

6. The impact resistance of concrete improved by addition of SF about 33 times more than plain concrete at $2.0 \%$ by volume. But using SSF without interlocking the spirals, there was no improvement in impact resistance compared with plain concrete.

7. The important and significant improvement was the great increase in impact resistance values, using interlocking spiral steel fibres. The increase was about 116, and 5.1 times that of plain concrete, and SFRC, respectively at 3.0\% by volume.

\section{References}

1 ACI 544. I R-96, State-of-the-art report on fiber reinforced concrete, Farmington Hills, Michigan: American Concrete Institute, 1996. 
2 American Society for Testing and Materials, Standard C-1 0 18, 1997, "Flexural Beam Test for the Testing of Steel Fibre Reinforced Concrete", ASTM, West Conshohocken.

3 Banthia .N, Gupta .P and Yan .C," Impact resistance of fibre reinforced wet-mix shot Crete", Part I : beam tests, Department of civil engineering, The University of British Columbia, Material and Structures, vol. 32, pp 563-570, Canada, 1999.

4 Ding-Yenning; Kusterle-Wolfgang, "Compressive stress-strain relationship of steel fibre-reinforced concrete at early age", Dali an University of Technology, Dali an, China, Cement and Concrete Research ,v 30,n 10, p 1573-1579, Oct, 2000.

5 Hannant D.J, "Fibre Cements and Fibre Concretes", JOHN WILEY \& SONS, Chichester. New York. Brisbane. Toronto, 1978.

6 Lars Kutzing, Girt Koenig "Design Principals for Steel Fibre Reinforced Concrete-A Fracture Mechanics Approach", University Leipzig.

7 Miao-Buquan; Chem- JennChuan; Yang-Chen An, "Influences of fiber content on properties of self-compacting steel fiber reinforced concrete" , Journal of the Chinese Institute of Engineers, v 26,n 4, p 523-530, July, 2003.

8 Midrand, Fibre reinforced concrete, published by the Cement\& Concrete Institute, 1997.

9 Song-PS; Hwang-S, "Mechanical properties of high-strength steel fiberreinforced concrete", Construction and Building Materials, v 18, n 9, p669-673, November 2004. 